Z. Klin. Chem. Klin. Biochem.

13. Jg. 1975, S. 109-115

\title{
Enzymatische Bestimmung des Gesamt-Cholesterins im Serum mit Analysenautomaten
}

\author{
Von J. Ziegenhorn \\ Boehringer Mannheim GmbH, Biochemica Werk Tutzing, Forschungszentrum
}

(Eingegangen am 12. November 1974)

\begin{abstract}
Eine einfache kinetische Methode zur automatischen Bestimmung des Gesamt-Cholesterins im Serum mittels Cholesterin-Esterase, Cholesterin-Oxydase, Katalase und Farbreaktion nach Hantzsch wurde entwickelt und das Verfahren auf die Analysenautomaten Braun SysteMatik, Eppendorf 5032, Greiner GSA II, Lars Ljungberg Autolab, Perkin-Elmer C4 und Perkin-Elmer C4B adaptiert.

Die einzelnen Varianten der Methode ergaben bei der Untersuchung von Präzision, Richtigkeit und Störanfälligkeit zufriedenstellende Resultate.
\end{abstract}

\section{Enzymatic method for the automated determination of total serum cholesterol}

A simple kinetic method for the automated determination of total serum cholesterol was developed using cholesterol esterase, cholesterol oxidase, catalase and the color reaction according to Hantzsch. The procedure has been adapted to the Braun SysteMatik, Greiner GSA II, Eppendorf 5032, Lars Ljungberg Autolab, Perkin-Elmer C4 and Perkin-Elmer C4B analyzers.

The variants of the method yielded satisfactory results with regard of precision, accuracy and sensitivity to interferences.

Eine erhöhte Cholesterin-Konzentration im Serum stellt einen wichtigen Risikofaktor für arteriosklerotische Gefäßerkrankungen dar (1-3). Die quantitative Analyse des Serum-Cholesterins gehört daher zu den im klinischchemischen Laboratorium häufig auszuführenden Untersuchungen.

Die bisher gebräuchlichen Verfahren zur Bestimmung dieser Substanz mit Hilfe von Analysenautomaten basieren im wesentlichen auf der Reaktion nach $\mathrm{Sal}$ kowski, Liebermann und Burchard (4-9). Wie die Untersuchungen verschiedener Autoren gezeigt haben, sind alle diese Methoden unspezifisch und störanfällig $(7,8)$. Ferner ist ihre Durchführung an Automaten infolge der Aggressivität der Reagenzien oft mit technischen Schwierigkeiten verbunden.

In der vorliegenden Arbeit wird eine enzymatische Methode zur Cholesterin-Bestimmung an Analysenautomaten beschrieben, die sich gegenüber den hergebrachten Verfahren durch eine bedeutend größere Spezifität und Praktikabilität auszeichnet. Bei dem neuen Verfahren werden die Cholesterin-Ester des Serums durch eine Cholesterin-Esterase gespalten und das freie Cholesterin durch eine Cholesterin-Oxydase in $\Delta^{4}$-Cholestenon und Wasserstoffperoxid umgewandelt (10). Das Wasserstoffperoxid wird mittels Katalase und Farbreaktion nach Hantzsch (11) nachgewiesen. Da man bei der Indikator-Reaktion für die Erreichung des Endwertes eine Inkubationsdauer von $60 \mathrm{~min}$ bei $37^{\circ} \mathrm{C}$ benötigt (10), wird die Bestimmung zur Abkürzung der Analysenzeit auf kinetischer Basis durchgeführt.

Von den bekannten Verfahren zur kinetischen Bestimmung von Konzentrationen ist die sog. "fixed-time". Methode an Analysenautomaten besonders einfach und genau ausführbar $(12,13)$. Bei diesem Verfahren läßt man die Nachweisreaktion über ein festgelegtes Zeitintervall ablaufen und mißt nach dieser Zeit die Konzentration des entstandenen bzw. verbrauchten Farbstoffs. Das Zeitintervall muß so gewählt werden, daß sich eine direkte Proportionalität $z$ wischen dem Meßsignal und der Anfangskonzentration der zu bestimmenden Substanz ergibt.

Aus theoretischen Betrachtungen verschiedener Autoren geht hervor, daß sich die Anwendung dieses Analysenverfahrens allgemein nur dann empfiehlt, wenn die Bestimmungsreaktion innerhalb des Meßzeitraums nach erster oder pseudoerster Ordnung abläuft $(12,13)$. Wie im nachstehenden gezeigt wird, lassen sich bei der enzymatischen Cholesterin-Bestimmung Versuchsbedingungen finden, unter denen diese Voraussetzung über einen großen Meßbereich erfüllt ist. Damit eröffnete sich hier die Möglichkeit zur Ausarbeitung empfindlicher "fixed-time"-Methoden. 


\section{Material und Methoden}

\section{Reagenzien ${ }^{1}$ )}

Die Cholesterin-Bestimmung wurde mit Hilfe der BiochemicaTest-Combination "Cholesterin, enzymatischer Farbtest" der Fa. Boehringer Mannheim GmbH durchgefuhrt. Die Testpackung enthält die Reagenzien Puffer/Katalase $(0,6 \mathrm{~mol} / 1$ Ammoniumphosphat-Puffer, $\mathrm{pH}=7 ; 1,7 \mathrm{~mol} / 1$ Methanol; $>700 \mathrm{kU} / \mathrm{l}$ Katalase), Chromogen (2,5 mol$/ 1$ Methanol; $0,42 \mathrm{~mol} / 1$ Acetylaceton; $21 \mathrm{~g} / 1$ Hydroxypolyäthoxydodecan), Cholesterin-Esterase $(\geqslant 7 \mathrm{kU} / \mathrm{l})$, Cholesterin-Oxydase $(\geqslant 4 \mathrm{kU} / \mathrm{l})$.

Aus diesen Reagenzien wurden die folgenden Gebrauchslösungen hergestellt:

1. Cholesterin-Reagenz $(0,57 \mathrm{~mol} / 1$ Ammoniumphosphat-Puffer, $\mathrm{pH}=7 ; 1,7 \mathrm{~mol} / 1 \mathrm{Methanol} ; 20 \mathrm{mmol} / 1$ Acetylaceton; $1 \mathrm{~g} / 1$ Hydroxypolyäthoxydodecan; $\geqslant 670 \mathrm{kU} / 1$ Katalase; $\geqslant 29$ bis $\geqslant 41 \mathrm{U} / 1$ Cholesterin-Esterase; $\geqslant 33$ bis $\geqslant 41 \mathrm{U} / 1$ CholesterinOxydase).

2. Leerwert-Reagenz (Zusammensetzung wie Cholesterin-Reagenz, jedoch ohne Cholesterin-Oxydase).

Die Lösungen waren bei $25^{\circ} \mathrm{C}$ einen Tag und bei $+4^{\circ} \mathrm{C}$ zwei Tage haltbar. Zur Kalibrierung wurde der wäßrige Standard Precimat Cholesterin (Boehringer Mannheim) verwendet, dessen Cholesterin-Gehalt $200 \mathrm{mg} / 100 \mathrm{ml}(5,17 \mathrm{mmol} / \mathrm{l})$ beträgt.

\section{Geräte}

Zur Bestimmung des Cholesterins wurden die Analysenautomaten Braun SỳsteMatik ${ }^{2}$ ), Eppendorf $5032^{3}$ ), Lars Ljungberg Autolab $^{4}$ ), Perkin-Elmer $\mathrm{C}^{5}$ ) und Perkin-Elmer $\mathrm{C}^{5} \mathrm{~B}^{5}$ ) eingesetzt. Die Reaktionsbedingungen des Greiner-GSA II-Automaten $^{6}$ ) wurden mit einem geeigneten Schüttelgerät simuliert. Die kinetischen Untersuchungen sowie die manuellen Cholesterin-Bestimmungen wurden am Photometer Eppendorf ${ }^{3}$ ) (thermostatisierter Küvettenhalter, Schreiber, Filter $\mathrm{Hg} 405 \mathrm{~nm}$ ) durchgefuihrt.

\section{Methoden}

Die Bestimmung von Cholesterin-Esterase und CholesterinOxydase sowie der manuelle Cholesterin-Test wurden nach 1.c. (10) durchgeführt. Es wurden stets Doppelbestimmungen vorgenommen und die Mittelwerte berechnet. Über Einzelheiten der technischen Durchführung der Cholesterin-Analyse an den Automaten wurde bereits an anderer Stelle berichtet $(14,15)$.

\section{Ergebnisse und Diskussion}

\section{Kinetik der Indikator-Reaktion}

Für Reaktionen erster oder pseudoerster Ordnung, bei denen aus einem Mol des umzusetzenden Stoffes ein Mol Farbstoff entsteht und bei denen ferner die Extinktion der Farbstoff-Konzentration linear proportional ist, gilt (16):

$$
\ln \left(E_{\infty}-E_{t}\right)=-k t+\ln E_{\infty} .
$$

Hier bezeichnet $\mathrm{E}_{\infty}$ die Extinktion nach vollständigem Ablauf der Reaktion, $E_{t}$ die Extinktion zu einem betrachteten Zeitpunkt $t$ und $k$ die Geschwindigkeitskonstante der Reaktion. Der Gleichung ist zu entnehmen,

\footnotetext{
1) Enzyme: Cholesterin-Esterase (EC 3.1.1.13), Cholesterin-Oxy: dase aus Nocardia erythropolis, Katalase (EC 1.11.1.6).

2) B. Braun Melsungen AG, Melsungen.

3) Eppendorf Gerätebau, Netheler \& Hinz GmbH, Hamburg.

$\left.{ }^{4}\right)$ AB Lars Ljungberg \& Co, Stockholm.

5) Bodenseewerk Perkin-Elmer \& $\mathrm{Co} . \mathrm{GmbH}$, Uberlingen.

$\left.{ }^{6}\right)$ Greiner Electronic AG, Langenthal, Schweiz.
}

daß man eine Gerade erhält, wenn der Ausdruck auf der linken Seite graphisch gegen die Zeit aufgetragen wird. Diese Gesetzmäßigkeit wurde in Abbildung 1 zur Demonstration der pseudomonomolekularen Reaktionsabschnitte bei der vollenzymatischen Cholesterin-Bestimmung benutzt. Man sieht, daß die Indikator-Reaktion nach einer kurzen Verzögerungsphase über einen großen Zeitraum formal einer Kinetik erster Ordnung folgt.

Technische Günde machten es an dén Automaten erforderlich, die nicht-lineare Startphase in die Messungen

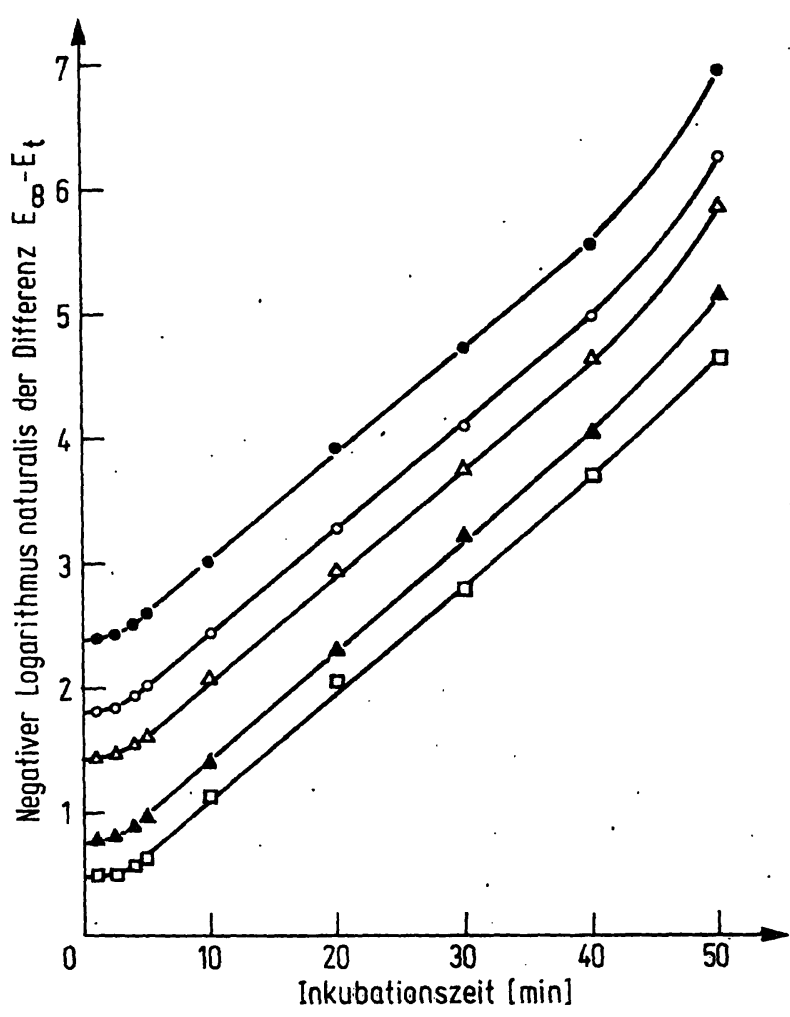

Abb. 1. Zeitlicher Verlauf der Indikator-Reaktion bei der enzymatischen Cholesterin-Bestimmung. Ansatz Perkin-Elmer C4B (vgl. Tab. 1 und 2). Durchführung der Messung am Photometer Eppendorf bei $\mathrm{Hg} 405 \mathrm{~nm}$ und $37^{\circ} \mathrm{C}$. Proben: Humanseren.

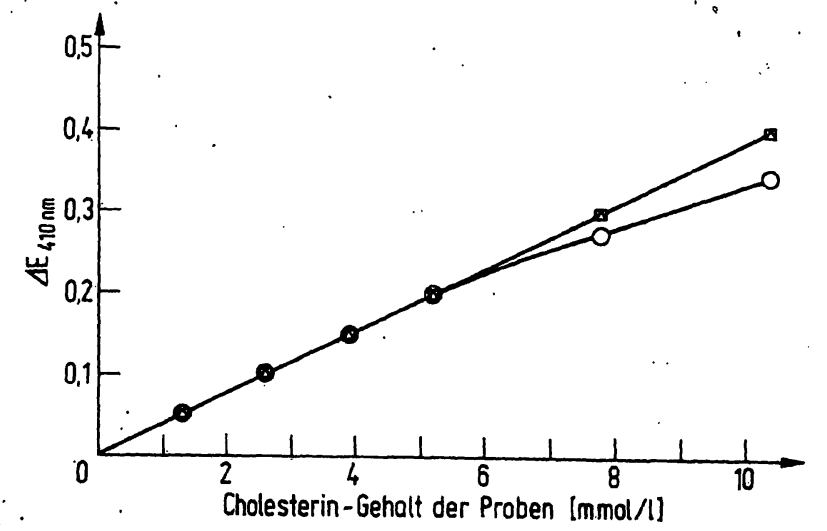

Abb. 2. Linearitätsbereich in Abhängigkeit von der CholesterinOxydase-Konzentration im Test. Experimentelle Einzelheiten vgl. Tabelle 1 und 2, Methode Perkin-Elmer C4B. Proben: Preciset Cholesterin. $\Delta: 49 \mathrm{U} / 1$ Cholesterin-Oxydase. $\square: 24,5 \mathrm{U} / 1$ Cholesterin-Oxydase. $0: 12,3 \mathrm{U} / 1$ Cholesterin-Oxydase. 
einzubeziehen. Dabei zeigte sich, daß sich auch unter diesen Umständen noch Zeitintervalle finden ließen, in denen eine lineare Beziehung $z$ wischen der Menge des gebildeten Farbstoffs und der Anfangskonzentration des Cholesterins bestand. An der Deutung dieses Sachverhalts wird gegenwärtig gearbeitet.

\section{Ermittlung der optimalen Reaktionsbedingungen}

Die Abbildung 2 gibt das Resultat eines charakteristischen Optimierungsversuchs wieder, der bei der Entwicklung der Methoden für die Analysenautomaten durchgeführt wurde. Aus diesem Versuch und zahlreichen anderen Experimenten, bei denen jeweils die spezifischen Eigenschaften der Automaten wie Dosiervolumina, Inkubationstemperatur, Inkubationszeit und Verschleppung berïcksichtigt werden mußten, folgten die in den Tabellen 1 und 2 zusammengestellten Bestimmungsansätze ${ }^{7}$ ).

Alle Methoden waren technisch einfach an den Automaten durchzuführen, da nur zwei verschiedene Reagenzgemische benötigt wurden. Die Gemische mußten nicht vor Beginn der Analyse auf die Temperatur des Bestimmungsansatzes gebracht werden; sie konnten vielmehr während des Gebrauchs bei Raumtemperatur oder bei etwa $+4^{\circ} \mathrm{C}$ aufbewahrt werden.

7) Da zur Entwicklung der Methode für den Greiner GSA II der Automat nicht zur Verfügung stand, wurden die Untersuchungen auf die Ermittlung der optimalen Reaktionsbedingungen beschränkt. Die weitere Ausarbeitung der Methode erfolgte durch Jaag und Küffer (15).
Die Inkubationszeiten lagen zwischen 8,7 und $25 \mathrm{~min}$, die Inkubationstemperaturen zwischen 37 und $45^{\circ} \mathrm{C}$. Die mit dem Greiner GSA II erreichte, bemerkenswert kurze Inkubationszeit von $8,7 \mathrm{~min}$ ist darauf zurückzuführen, daß hier ein ununterbrochenes Mischen der Prozeßflüssigkeit erfolgt.

Die Berechnung der Cholesterin-Konzentration im Serum erfolgte bei allen Methoden unter Bezugnahme auf den wäßrigen Standard. Innerhalb einer Meßserie konnte jeweils mit einem aus der Standard-Extinktion ermittelten Faktor gearbeitet werden.

\section{Charakterisierung der Methoden}

Bei allen Methoden lag im Bereich von 0-12,93 mmol/1 (0-500 mg/100 ml) Cholesterin eine lineare Beziehung zwischen Extinktion und Cholesterin-Konzentration vor (Abb. 2, 3, Tab. 3). Proben mit einem Cholesterin-Gehalt über 12,93 mmol/1 ließen sich nach entsprechender Verdünnung mit physiologischer NaCl-Lösung bestimmen. Durch den Verdünnungsschritt wurde die Richtigkeit der Meßwerte nicht beeinflußt. Die Empfindlichkeit der Methoden im niedrigen Konzentrationsbereich war ausreichend groß (Abb. 2, 3).

Für die Präzision in der Serie ergaben sich auf den Automaten trotz des Vorliegens von kinetischen Verfahren größtenteils bessere Resultate (Tab. 3) als im manuellen enzymatischen Test (10). Die Präzision von

Tab. 1. Bestimmungsansätze

I = Proben-Ansatz $\quad$ II $=$ Leerwert-Ansatz $\quad$ Schichtdicke $=1 \mathrm{~cm}$

\begin{tabular}{|c|c|c|c|c|c|c|c|}
\hline & & $\begin{array}{l}\text { Braun } \\
\text { SysteMatik }\end{array}$ & $\begin{array}{l}\text { Eppendorf } \\
5032\end{array}$ & $\begin{array}{l}\text { Greiner } \\
\text { GSA II }\end{array}$ & $\begin{array}{l}\text { L. Ljung- } \\
\text { berg Autolab }\end{array}$ & $\begin{array}{l}\text { Perkin-Elmer } \\
\text { C4 }\end{array}$ & $\begin{array}{l}\text { Perkin-Elmer } \\
\text { C4B }\end{array}$ \\
\hline Probe [ml] & I & $\begin{array}{l}0,02 \\
0,02\end{array}$ & $\begin{array}{l}0,01 \\
0,01\end{array}$ & $\begin{array}{l}0,02 \\
0,02\end{array}$ & $\begin{array}{l}0,01 \\
0,01\end{array}$ & $\begin{array}{l}0,02 \\
0,02\end{array}$ & $\begin{array}{l}0,01 \\
0,01\end{array}$ \\
\hline $\begin{array}{l}\text { Cholesterin- } \\
\text { Reagenz [ml] }\end{array}$ & II & $\begin{array}{l}- \\
-\end{array}$ & 1,0 & 2,5 & 1,7 & 2,5 & 1,7 \\
\hline $\begin{array}{l}\text { Leerwert- } \\
\text { Reagenz [ml] }\end{array}$ & I & $\begin{array}{l}2,5 \\
2,5\end{array}$ & $\overline{1,0}$ & $\overline{2,5}$ & $\overline{1,7}$ & $\overline{2,5}$ & $\overline{1,7}$ \\
\hline $\begin{array}{l}\text { Cholesterin-Oxydase- } \\
\text { Lösung*) [ml] }\end{array}$ & II & $\begin{array}{l}0,5 \\
-\end{array}$ & $\overline{-}$ & $\overline{-}$ & $\overline{-}$ & $\overline{-}$ & $\overline{-}$ \\
\hline bidest. Wasser [ml] & I & $\overline{0,5}$ & - & $\begin{array}{l}0,1 \\
0,1\end{array}$ & - & - & - \\
\hline $\begin{array}{l}\text { Inkubations- } \\
\text { temperatur }\left[{ }^{\circ} \mathrm{C}\right]\end{array}$ & & 45 & 37 & 37 & 37 & 40 & 37 \\
\hline Inkubationszeit [min] & & 20 & 20 & 8,7 & 25 & 20 & 20 \\
\hline $\begin{array}{l}\text { Umsatz (\%)**)/ } \\
\text { Inkubationszeit }\end{array}$ & & 89 & 82 & 54 & 81 & 90 & 86 \\
\hline Wellenlänge [nm] & & $\mathrm{Hg} 405$ & Hg 405 & $\mathrm{Hg} 405$ & 410 & 410 & 410 \\
\hline
\end{tabular}

*) Zusammensetzung: $>160 \mathrm{U} / 1$ Cholesterin-Oxydase.

**) Formaldehyd-Umsatz bei der Indikator-Reaktion. 
Tab. 2. Konzentrationen im Test

I = Proben-Ansatz $\quad$ II = Leerwert-Ansatz

\begin{tabular}{|c|c|c|c|c|c|c|c|}
\hline Substanz & & $\begin{array}{l}\text { Braun- } \\
\text { SysteMatik }\end{array}$ & $\begin{array}{l}\text { Eppendorf } \\
5032\end{array}$ & $\begin{array}{l}\text { Greiner } \\
\text { GSA II }\end{array}$ & $\begin{array}{l}\text { L. Ljung- } \\
\text { berg Autolab }\end{array}$ & $\begin{array}{l}\text { Perkin-Elmer } \\
\text { C4 }\end{array}$ & $\begin{array}{l}\text { Perkin-Elmer } \\
\text { C4B }\end{array}$ \\
\hline $\begin{array}{l}\text { Ammoniumphos- } \\
\text { phat-Puffer, } \\
\text { pH = } 7[\mathrm{~mol} / 1]\end{array}$ & II & $\begin{array}{l}0,47 \\
0,47\end{array}$ & $\begin{array}{l}0,56 \\
0,56\end{array}$ & $\begin{array}{l}0,54 \\
0,54\end{array}$ & $\begin{array}{l}0,57 \\
0,57\end{array}$ & $\begin{array}{l}0,57 \\
0,57 \\
\end{array}$ & $\begin{array}{l}0,57 \\
0,57\end{array}$ \\
\hline Methanol [mol/1] & $\begin{array}{r}\text { I } \\
\text { II }\end{array}$ & $\begin{array}{l}1,4 \\
1,4\end{array}$ & $\begin{array}{l}1,7 \\
1,7\end{array}$ & $\begin{array}{l}1,6 \\
1,6\end{array}$ & $\begin{array}{l}1,7 \\
1,7\end{array}$ & $\begin{array}{l}1,7 \\
1,7\end{array}$ & $\begin{array}{l}1,7 \\
1,7\end{array}$ \\
\hline $\begin{array}{l}\text { Acetylaceton } \\
{[\mathrm{mmol} / \mathrm{l}]}\end{array}$ & $\begin{array}{r}\text { I } \\
\text { II }\end{array}$ & $\begin{array}{l}17 \\
17\end{array}$ & $\begin{array}{l}20 \\
20\end{array}$ & $\begin{array}{l}19 \\
19\end{array}$ & $\begin{array}{l}20 \\
20\end{array}$ & $\begin{array}{l}20 \\
20\end{array}$ & $\begin{array}{l}20 \\
20\end{array}$ \\
\hline $\begin{array}{l}\text { Hydroxypolyäthoxy- } \\
\text { dodecan }[\mathrm{g} / 1]\end{array}$ & II & $\begin{array}{l}0,83 \\
0,83\end{array}$ & $\begin{array}{l}0,99 \\
0,99\end{array}$ & $\begin{array}{l}0,95 \\
0,95\end{array}$ & $\begin{array}{l}0,99 \\
0,99\end{array}$ & $\begin{array}{l}0,99 \\
0,99\end{array}$ & $\begin{array}{l}0,99 \\
0,99\end{array}$ \\
\hline Katalase $[\mathrm{kU} / \mathrm{l}]$ & I & $\begin{array}{l}\geqslant 550 \\
\geqslant 550\end{array}$ & $\begin{array}{l}\geqslant 660 \\
\geqslant 660\end{array}$ & $\begin{array}{l}\geqslant 640 \\
\geqslant 640\end{array}$ & $\begin{array}{l}\geqslant 660 \\
\geqslant 660\end{array}$ & $\begin{array}{l}\geqslant 660 \\
\geqslant 660\end{array}$ & $\begin{array}{l}\geqslant 660 \\
\geqslant 660\end{array}$ \\
\hline $\begin{array}{l}\text { Cholesterin- } \\
\text { Esterase [U/1] }\end{array}$ & II & $\begin{array}{l}\geqslant 24 \\
\geqslant 24\end{array}$ & $\begin{array}{l}\geqslant 35 \\
\geqslant 35\end{array}$ & $\begin{array}{l}\geqslant 39 \\
\geqslant 39\end{array}$ & $\begin{array}{l}\geqslant 33 \\
\geqslant 33\end{array}$ & $\begin{array}{l}\geqslant 29 \\
\geqslant 29\end{array}$ & $\begin{array}{l}\geqslant 33 \\
\geqslant 33\end{array}$ \\
\hline $\begin{array}{l}\text { Cholesterin- } \\
\text { Oxydase }[U / 1]\end{array}$ & II & $\begin{array}{l}\geqslant 27 \\
-\end{array}$ & $\begin{array}{l}\geqslant 39 \\
-\end{array}$ & $\begin{array}{l}\geqslant 39 \\
-\end{array}$ & $\begin{array}{l}\geqslant 37 \\
-\end{array}$ & $\begin{array}{l}\geqslant 33 \\
-\end{array}$ & $\begin{array}{l}\geqslant 37 \\
-\end{array}$ \\
\hline
\end{tabular}

Tab. 3. Präzision der Cholesterin-Bestimmung in der Serie



*) Boehringer Mannheim GmbH.

**) Serum stark trüb. 
Tab. 4. Methodenvergleich

$\mathbf{x}$-Werte $=$ manuell bestimmte Werte. $\mathbf{y}$-Werte $=$ automatisch bestimmte Werte. Untersuchter Konzentrationsbereich für Cholesterin im Serum: $1,29-12,93 \mathrm{mmol} / \mathrm{l}$.

\begin{tabular}{|c|c|c|c|c|c|}
\hline Methode & Proben & $\begin{array}{l}\text { Anzahl der } \\
\text { Wertepaare } \\
\mathbf{n}\end{array}$ & $\begin{array}{l}\text { Regressions-Gerade } \\
y=b x+a\end{array}$ & $\begin{array}{l}\text { Korrelations- } \\
\text { Koeffizient } \\
\text { r }\end{array}$ & $\begin{array}{l}\text { Konfidenzbereich für } \\
\left.\text { wirkliche Steigung } \beta^{*}\right) \\
<\beta<\end{array}$ \\
\hline Braun SysteMatik & Humanseren & 75 & $y=1,00 x-1,15$ & 0,994 & $0,98<\beta<1,03$ \\
\hline Eppendorf 5032 & Humanseren & 62 & $y=0,98 x+1,98$ & 0,997 & $0,96<\beta<1,00$ \\
\hline Greiner GSA II & Humanseren & 17 & $y=0,99 x+2,63$ & 0,998 & $0,94<\beta<1,03$ \\
\hline L. Ljungberg Autolab & Humanseren & 50 & $y=0,98 x+0,97$ & 0,992 & $0,94<\beta<1,01$ \\
\hline Perkin-Elmer C4 & Humanseren & 100 & $y=0,99 x+2,76$ & 0,996 & $0,98<\beta<1,01$ \\
\hline Perkin-Elmer C4B & Humanseren & 57 & $y=0,97 x+2,89$ & 0,996 & $0,95<\beta<1,00$ \\
\hline
\end{tabular}

*) berechnet nach 1.c. (18) unter Zugrundelegung einer Regression 1. Art und einer Irrtumswahrscheinlichkeit von 0,05.

Tab. 6. Cholesterin-Meßwerte in kommerziellen Kontroll-Seren. $A=$ automatischer Meßwert. $M=$ manueller Meßwert (enzymatische Methode). Mittelwerte aus jeweils zwei Bestimmungen. Cholesterin-Gehalt in mg/100 ml.

\begin{tabular}{|c|c|c|c|c|c|c|c|c|c|c|c|}
\hline \multirow[t]{2}{*}{ Kontroll-Serum } & \multirow[t]{2}{*}{$\begin{array}{l}\text { Soll- } \\
\text { wert*) }\end{array}$} & \multicolumn{2}{|c|}{ Braun SysteMatik } & \multicolumn{2}{|c|}{ Eppendorf 5032} & \multicolumn{2}{|c|}{$\begin{array}{l}\text { L. Ljungberg } \\
\text { Autolab }\end{array}$} & \multicolumn{2}{|c|}{ Perkin-Elmer C4 } & \multicolumn{2}{|c|}{ Perkin-Elmer C4B } \\
\hline & & $\mathbf{A}$ & $\mathbf{M}$ & $\mathbf{A}$ & $\mathbf{M}$ & $\mathbf{A}$ & $\mathbf{M}$ & $\mathbf{A}$ & $\mathbf{M}$ & $\mathbf{A}$ & $\mathbf{M}$ \\
\hline $\begin{array}{l}\text { Precilip } \\
\text { Nr. } 319 \text { B }\end{array}$ & 169 & 144 & 142 & 141 & 140 & 140 & 145 & 147 & 142 & 146 & 148 \\
\hline $\begin{array}{l}\text { Versatol**) } \\
\text { Nr. } 2455121\end{array}$ & 147 & 134 & 136 & 129 & 132 & 134 & 140 & 136 & 132 & 137 & 132 \\
\hline $\begin{array}{l}\text { Versatol-A**) } \\
\text { Nr. } 2034033\end{array}$ & 95 & 75 & 76 & 79 & 80 & 82 & 86 & 79 & 76 & 81 & 80 \\
\hline $\begin{array}{l}\text { Moni-trol I***) } \\
\text { Nr. LTD-125 A, B }\end{array}$ & 163 & 140 & 144 & 144 & 147 & 142 & 140 & 143 & 144 & 144 & 148 \\
\hline $\begin{array}{l}\text { Moni-trol II***) } \\
\text { Nr. PTD-32 A, B }\end{array}$ & 142 & 103 & 105 & 104 & 105 & 104 & 108 & 103 & 105 & 106 & 105 \\
\hline $\begin{array}{l}\text { CHOLES-TROL } \\
\text { D***) } \\
\text { Nr. CTD-314 }\end{array}$ & 367 & 308 & 307 & 298 & 307 & 309 & 306 & 314 & 307 & 301 & 307 \\
\hline
\end{tabular}

*) Liebermann-Burchard-Reaktion ohne Extraktion, $\mathrm{mg} / 100 \mathrm{ml}$.

**) General Diagnostics Division, Morris Plains, N.J., USA.

***) Dade Division, Miami, Fla., USA.

Tab. 5. Wiederfindungsversuche. Aufstockung von Humanseren mit Preciset Cholesterin. Methode Eppendorf 5032. Mittelwerte aus jeweils zwei Bestimmungen.

\begin{tabular}{llllr}
\hline $\begin{array}{l}\text { Serum } \\
\text { Nr. }\end{array}$ & $\begin{array}{l}\text { Cholesterin- } \\
\text { Konzen- } \\
\text { tration } \\
\text { [mmol/1] }\end{array}$ & $\begin{array}{l}\text { Zugesetzte } \\
\text { Menge } \\
\text { Cholesterin } \\
\text { [mmol/1] }\end{array}$ & $\begin{array}{l}\text { Gefundene } \\
\text { Menge } \\
\text { Cholesterin } \\
\text { [mmol/1] }\end{array}$ & $\begin{array}{l}\text { Wieder- } \\
\text { findung } \\
\text { [\%] }\end{array}$ \\
\hline 1 & 5,97 & 0,88 & 6,78 & 99 \\
2 & 5,97 & 1,45 & 7,68 & 103 \\
3 & 7,22 & 0,62 & 7,63 & 97 \\
4 & 7,22 & 1,03 & 8,22 & 100 \\
5 & 5,85 & 0,91 & 6,70 & 99 \\
6 & 5,85 & 1,63 & 7,50 & 100 \\
7 & 5,43 & 2,46 & 8,02 & 102 \\
\hline
\end{tabular}

Tab. 7. Einfluß einer Hämolyse auf die Cholesterin-Bestimmung

\begin{tabular}{lll}
$\begin{array}{l}\text { Hämoglobin-Gehalt } \\
\text { des Serums } \\
\text { [g/1] }\end{array}$ & $\begin{array}{l}\text { Eppendorf 5032 } \\
\text { Cholesterin-Meßjwert*) }\end{array}$ & $\begin{array}{c}\text { Perkin-Elmer C4 } \\
\text { [mol/1] }\end{array}$ \\
\hline 0 & 4,84 & 4,78 \\
1,20 & 4,86 & 4,84 \\
2,40 & 4,78 & 4,84 \\
3,60 & 4,73 & 4,73 \\
4,80 & 4,73 & 4,86 \\
6,00 & 4,68 & 4,89 \\
7,20 & 4,81 & 4,84 \\
8,40 & 4,73 & 4,78 \\
10,80 & 4,73 & 4,66 \\
\hline
\end{tabular}

*) Mittelwert aus zwei Bestimmungen. 
Tab. 8. Einfluß einer Lipämie auf die Cholesterin-Bestimmung. Aufstockung von Humanseren mit Preciset Cholesterin. (I) $=$ Meßwert Braun SysteMatik. (II) = Meßwert Perkin-Elmer C4B. Mittelwerte aus jeweils zwei Bestimmungen.

\begin{tabular}{|c|c|c|c|c|c|}
\hline $\begin{array}{l}\text { Serum } \\
\text { Nr. }\end{array}$ & $\begin{array}{l}\text { Triglycerid- } \\
\text { Konzentration } \\
{[\mathrm{mmol} / \mathrm{l}]}\end{array}$ & $\begin{array}{l}\text { Cholesterin- } \\
\text { Konzentration } \\
{[\mathrm{mmol} / \mathrm{l}]}\end{array}$ & $\begin{array}{l}\text { Zugesetzte Menge } \\
\text { Cholesterin } \\
{[\mathrm{mmol} / \mathrm{l}]}\end{array}$ & $\begin{array}{l}\text { Gefundene Menge } \\
\text { Cholesterin } \\
\text { [mmol/1] }\end{array}$ & $\begin{array}{l}\text { Wiederfindung } \\
{[\%]}\end{array}$ \\
\hline 1 & 4,52 & $\begin{array}{l}6,83 \text { (I) } \\
6,78 \text { (II) }\end{array}$ & $\begin{array}{l}1,76 \\
1,76\end{array}$ & $\begin{array}{l}8,51 \text { (I) } \\
8,43 \text { (II) }\end{array}$ & $\begin{array}{l}99 \\
99\end{array}$ \\
\hline 2 & 8,59 & $\begin{array}{l}5,48 \text { (I) } \\
5,38 \text { (II) }\end{array}$ & $\begin{array}{l}2,43 \\
2,43\end{array}$ & $\begin{array}{l}7,84 \text { (I) } \\
7,79 \text { (II) }\end{array}$ & $\begin{array}{r}99 \\
100\end{array}$ \\
\hline 3 & 22,60 & $\begin{array}{l}9,36 \text { (I) } \\
9,41 \text { (II) }\end{array}$ & $\begin{array}{l}0,47 \\
0,47\end{array}$ & $\begin{array}{l}9,72 \text { (I) } \\
9,67 \text { (II) }\end{array}$ & $\begin{array}{l}99 \\
98\end{array}$ \\
\hline
\end{tabular}



Abb. 3. Extinktionsdifferenz in Abhängigkeit von der Cholesterin-Konzentration.

$\triangle$ : Meßwert Eppendorf 5032. ๑: Meßwert Perkin-Elmer C4. o: Meßwert Perkin-Elmer C4B. Proben: Humanseren. Ermittlung des Cholesterin-Gehalts der Proben mit manueller enzymatischer Methode.

Tag zu Tag, die mit Hilfe des Kontrollserums Precilip ${ }^{8}$ ) ermittelt wurde, war mit Variationskoeffizienten von $0,9-2,7 \%$ bei einem Meßzeitraum von jeweils $6-8$ Tagen zufriedenstellend.

Zur Überprüfung der Richtigkeit wurden die Methoden mit dem manuellen enzymatischen Test verglichen, der seinerseits gut mit der Referenz-Methode nach $A$ bell et al. (17) korreliert (10). Die in Tabelle 4 wiedergegebenen Versuchsergebnisse belegen, daß die AutomatenMethoden Cholesterin-Meßwerte lieferten, die mit den

8) Boehringer Mannheim GmbH.
Tab. 9. Einfluß von Bilirubin auf die Cholesterin-Bestimmung

\begin{tabular}{|c|c|c|c|}
\hline \multicolumn{2}{|c|}{ Serum Bilirubin-Gehalt } & \multirow{2}{*}{$\begin{array}{l}\text { Eppendorf } 5032 \\
\text { Cholesterin-Meßw }\end{array}$} & \multirow{2}{*}{$\begin{array}{l}\text { Perkin-Elmer C4B } \\
\text { rt) }[\mathrm{mmol} / 1]\end{array}$} \\
\hline Nr. & {$[\mathrm{mmol} / 1]$} & & \\
\hline 1 & $\begin{array}{r}0 \\
0,17\end{array}$ & $\begin{array}{l}2,77 \\
2,69\end{array}$ & \\
\hline 2 & $\begin{array}{r}0 \\
0,17\end{array}$ & & $\begin{array}{l}3,13 \\
3,05\end{array}$ \\
\hline 3 & $\begin{array}{r}0 \\
0,17\end{array}$ & $\begin{array}{l}5,17 \\
5,20\end{array}$ & \\
\hline 4 & $\begin{array}{r}0 \\
0,17\end{array}$ & & $\begin{array}{l}6,83 \\
6,88\end{array}$ \\
\hline 5 & $\begin{array}{r}0 \\
0,34\end{array}$ & $\begin{array}{l}2,35 \\
2,51\end{array}$ & \\
\hline 6 & $\begin{array}{r}0 \\
0,34\end{array}$ & & $\begin{array}{l}2,69 \\
2,61\end{array}$ \\
\hline 7 & $\begin{array}{r}0 \\
0,34\end{array}$ & $\begin{array}{l}4,42 \\
4,47\end{array}$ & \\
\hline 8 & $\begin{array}{r}0 \\
0,34\end{array}$ & & $\begin{array}{l}5,87 \\
5,85\end{array}$ \\
\hline 9 & $\begin{array}{r}0 \\
0,68\end{array}$ & $\begin{array}{l}1,58 \\
1,60\end{array}$ & \\
\hline 10 & $\begin{array}{r}0 \\
0,68 .\end{array}$ & & $\begin{array}{l}1,78 \\
1,76\end{array}$ \\
\hline 11 & $\begin{array}{r}0 \\
0,68\end{array}$ & $\begin{array}{l}2,95 \\
3,10\end{array}$ & \\
\hline 12 & $\begin{array}{r}0 \\
0,68\end{array}$ & & $\begin{array}{l}3,91 \\
4,11\end{array}$ \\
\hline
\end{tabular}

*) Mittelwert aus zwei Bestimmungen.

Tab. 10. Einfluß von Antikoagulantien auf die CholesterinBestimmung

\begin{tabular}{lcll}
\hline Antikoagulans & $\begin{array}{l}\text { Konzentration } \\
\text { im Serum }\end{array}$ & $\begin{array}{l}\text { Eppendorf } \\
5032\end{array}$ & $\begin{array}{l}\text { Perkin- } \\
\text { Elmer C4 }\end{array}$ \\
& {$[\mathrm{mg} / \mathrm{ml}]$} & Cholesterin-Meßwert*) [mmol/1] \\
\hline & 0 & 5,59 & 5,53 \\
\hline Citrat & 1 & 5,56 & 5,48 \\
Oxalat & 30 & 5,51 & 5,51 \\
& 1 & 5,59 & 5,56 \\
Fluorid & 30 & 5,51 & 5,38 \\
& 2 & 5,61 & 5,48 \\
Heparin & 10 & $5,5.9$ & 5,51 \\
& 30 & 5,59 & 5,46 \\
EDTA & 0,2 & 5,61 & 5,48 \\
& 2 & 5,59 & 5,48 \\
& 1 & 5,59 & 5,56 \\
& 10 & 5,48 & 5,48 \\
\hline
\end{tabular}

*) Mittelwert aus zwei Bestimmungen. 
manuell erhaltenen Werten ausgezeichnet übereinstimmten. Nach Zusatz des wäßrigen Standards Preciset Cholesterin $^{8}$ ) zu Humanseren wirde die berechnete Menge quantitativ wiedergefunden (Beispiel Tab. 5). Die in kommerziellen Kontroll-Seren gemessenen Cholesterin-Konzentrationen lagen unter den angegebenen Sollwerten (Tab. 6). Dies ist verständlich, da mit den enzymatischen Methoden nur das Cholesterin (10), mit den zur Sollwert-Ermittlung eingesetzten chemischen Methoden hingegen auch noch andere Serum-Bestandteile wie Bilirubin und Serum-Proteine erfaßt werden $(7,8)$.

Hämolyse, Lipämie, Bilirubin, Antikoagulantien sowie die Pharmaka Ascorbinsäure, Novaminsulfon und $\alpha$ Methyl-DOPA beeinflußten die Cholesterin-Bestimmungen nicht (Beispiele Tab. 7-11).

Die beschriebenen Methoden erwiesen sich im Rahmen der bisherigen Untersuchungen als spezifisch, störunanfällig und einfach durchfuihrbar. Sie werden gegenwärtig in klinisch-chemischen Routinelabors einer ausgedehnten Erprobung unterzogen.
An der technischen Bearbeitung waren die folgenden Mitarbeiter beteiligt: Fräulein J. Bader, Fräulein $H$. Hoffmann und Frau K. Stephani.

Tab. 11. Beeinflussung der Cholesterin-Bestimmung durch Pharmaka in vitro. Methode Perkin-Elmer C4.

\begin{tabular}{|c|c|c|c|}
\hline Serum & Pharmakon & $\begin{array}{l}\text { Konzentration } \\
\text { im Serum } \\
{[\mathrm{g} / 1]}\end{array}$ & $\begin{array}{l}\text { Cholesterin-Meß- } \\
\text { wert*) } \\
{[\mathrm{mmol} / \mathrm{l}]}\end{array}$ \\
\hline 1 & $\begin{array}{l}\text { Ascorbinsäure } \\
\text { Ascorbinsäure } \\
\text { Novaminsulfon }\end{array}$ & $\begin{array}{l}- \\
0,25 \\
0,50 \\
0,50\end{array}$ & $\begin{array}{l}5,28 \\
5,38 \\
5,33 \\
5,17\end{array}$ \\
\hline 2 & $\begin{array}{l}\text { Ascorbinsäure } \\
\text { Ascorbinsäure } \\
\text { Novaminsulfon }\end{array}$ & $\begin{array}{l}\overline{0}, 25 \\
0,50 \\
0,50\end{array}$ & $\begin{array}{l}4,71 \\
4,78 \\
4,76 \\
4,58\end{array}$ \\
\hline 3 & $\begin{array}{l}\text { Ascorbinsäure } \\
\text { Novaminsulfon } \\
\alpha \text {-Methyl-DOPA }\end{array}$ & $\begin{array}{l}\overline{1,0 * *)} \\
1,16 * *) \\
0,25 * *)\end{array}$ & $\begin{array}{l}4,91 \\
4,94 \\
4,78 \\
4,94\end{array}$ \\
\hline
\end{tabular}

*) Mittelwert aus zwei Bestimmungen.

**) Ein Liter Serum enthält hier die Tages-Einzelmaximaldosis.

\section{Literatur}

1. Lynen, F. (1972), Naturwiss. Rundsch. 25, 382-391.

2. Irsigler, K. (1973), Wien. Klin. Wochenschr. 85, 195.

3. Schwandt, P. (1973), Internist 14, 325-329.

4. Salkowski, E. (1872), Pflügers Arch. 6, 207-212.

5. Liebermann, C. (1885), Chem. Ber. 18, 1803-1809.

6. Burchard, H. (1889), Dissertation, Rostock.

7. Brown, S. S. (1973), Ann. Clin. Biochem. 10, 146-154.

8. Tonks, D. B. (1967), Clin. Biochem. 1, 12-29.

9. Watson, D. (1960), Clin. Chim. Acta 5, 637-643.

10. Röschlau, P., Bernt, E. \& Gruber, W. (1974), diese Z. 12, 403-407.

11. Nash, T. (1953), Biochem. J. 55, 416-421.

12. Pardue, H. L. (1969), Advan. Anal. Chem. Instrum. 7 141-206.

13. Ingle, Jr., J. D. \& Crouch, S. R. (1971), Anal. Chem. 43, 697-701.
14. Vorläufige Arbeitsanleitungen "Cholesterin, enzymatischer Farbtest" für Braun SysteMatik, Eppendorf 5032, Lars Ljungberg Autolab, Perkin-Elmer C4 und Perkin-Elmer C4B (1974), Boehringer Mannheim GmbH, Mannheim.

15. Jaag, P. \& Küffer, H. (1974), in Handbook Greiner Electronic Selective Analyzer GSA II, Greiner Electronic AG, Langenthal, Schweiz.

16. Hewitt, T. E. \& Pardue, H. L. (1973), Clin. Chem. 19, 1128-1134.

17. Abell, L. L., Levy, B. B., Brodie, B. B. \& Kendall, F. E. (1952), J. Biol. Chem. 195, 357-366.

18. Kreyszig, E. (1968), Statistische Methoden und ihre Anwendung, Verlag Vandenhoeck \& Ruprecht, Göttingen.

Dr. J. Ziegenhorn

Boehringer Mannheim GmbH Biochemica Werk Tutzing

8132 Tutzing/Obb.

Postfach 120 
